Observatório de Inovação do Turismo

\title{
Hospitalidade nos cruzeiros marítimos: conceitos e preceitos para segurança e bem-estar do viajante
}

Hospitality in cruise ships: concepts and precepts for traveler safety and health

Hospitalidad en cruceros marítimos: conceptos y preceptos de seguridad y bienestar para los pasajeros

Dennis Minoru Fujita

Heitor Franco de Andrade Júnior

\section{Resumo}

No presente artigo, realiza-se pesquisa de revisão qualitativa descritiva em relação à questão de segurança e bem-estar dos passageiros em cruzeiros marítimos no Brasil, preocupação surgida em virtude de aumento considerável nos últimos anos. Nesse sentido, parte-se dos conceitos básicos de hospitalidade e seu desdobramento nos cruzeiros marítimos como meio de referenciar a necessidade de atenção para as condições mínimas de segurança nas atividades turísticas, tendo-se como objetivo principal a descrição geral de equipamentos e serviços oferecidos a bordo nos cruzeiros como parâmetro mínimo, visto que tais estruturas são regulamentadas internacionalmente por normas oriundas da IMO - International Maritime Organization -, agência vinculada às Nações Unidas, 
e fiscalizados pela Marinha brasileira em conjunto com a ANVISA - Agência Nacional de Vigilância Sanitária.

Palavras-chave: hospitalidade, cruzeiros marítimos, segurança e bem-estar

\begin{abstract}
:
This article provides a descriptive qualitative review research of security and welfare of passengers at cruise ships in Brazil, due to the significant increase of tourists in the past few years. In this sense, we analyze the basic concepts of hospitality and its development in the cruise ships as an example of minimum conditions of security in tourism activities, conducting to the main objective of this paper to realize a general description of facilities and services offered on board as a minimum standard. Such structures are regulated internationally by rules from IMO - International Maritime Organization -, a United Nations special agency, being supervised in country by the Brazilian Navy in partnership with ANVISA - Agência Nacional de Vigilância Sanitária.
\end{abstract}

Key words: hospitality, cruise ships, safety and welfare

\title{
Resumen:
}

Este artículo presenta una investigación descriptiva cualitativa sobre la cuestión de la seguridad y el bienestar de los pasajeros en Brasil, situación preocupante debido al considerable aumento en los últimos años. En este sentido, utilizamos los conceptos básicos de hospitalidad como una referencia y su impacto en el crucero como un ejemplo de la necesidad de atención en materia de seguridad mínima en las actividades turísticas, com el objetivo de realizar una descripción general del equipo y los servicios ofrecidos por cruceros como estándar mínimo, 
puesto que estas estructuras están reguladas internacionalmente por las normas de la IMO - Organización Marítima Internacional -, un organismo vinculado a las Naciones Unidas, siendo supervisado por la Marina de Brasil, en conjunto con la ANVISA - Agência Nacional de Vigilância Sanitária.

Palabras clave: hospitalidad, cruceros, seguridad y Bienestar

\section{Introdução}

A atividade turística no Brasil está em desenvolvimento crescente apresentando a marca de viagens internas em 197 milhões, em 2012, contra 190,8 milhões, em 2011. O número de brasileiros que viajaram pelo País chegou a sessenta milhões, superando o recorde de 58,9 milhões de 2011, segundo análise do Departamento de Estudos e Pesquisas do Ministério do Turismo (2013).

Quanto ao fluxo de turismo receptivo internacional no Brasil, constatase o aumento no decurso dos anos. Em 2013, por exemplo, 5.676.843 estrangeiros desembarcaram no Brasil pelas mais diferentes formas e vias de acesso (Tabela 1). 
Tabela 1. Chegadas de turistas ao Brasil, entre os anos de 1970-2012

\begin{tabular}{|c|c|c|c|c|c|c|c|}
\hline \multicolumn{8}{|c|}{ Chegadas de turistas } \\
\hline Ano & Total & Ano & Total & Ano & Total & Ano & Total \\
\hline 1970 & 249.900 & 1982 & 1.146 .681 & 1994 & 1.853 .301 & 2006 & 5.017 .251 \\
\hline 1971 & 287.926 & 1983 & 1.420 .481 & 1995 & 1.991 .416 & 2007 & 5.025 .834 \\
\hline 1972 & 342.961 & 1984 & 1.595 .726 & 1996 & 2.665 .508 & 2008 & 5.050 .099 \\
\hline 1973 & 399.127 & 1985 & 1.735 .982 & 1997 & 2.849 .750 & 2009 & 4.802 .217 \\
\hline 1974 & 480.267 & 1986 & 1.934 .091 & 1998 & 4.818 .084 & 2010 & 5.161 .379 \\
\hline 1975 & 517.967 & 1987 & 1.929 .053 & 1999 & 5.107 .169 & 2011 & 5.433 .354 \\
\hline 1976 & 555.967 & 1988 & 1.742 .939 & 2000 & 5.313 .463 & 2012 & 5.676 .843 \\
\hline 1977 & 634.595 & 1989 & 1.402 .897 & 2001 & 4.772 .575 & & \\
\hline 1978 & 784.316 & 1990 & 1.091 .067 & 2002 & 3.784 .898 & & \\
\hline 1979 & 1.081 .799 & 1991 & 1.228 .178 & 2003 & 4.132 .847 & & \\
\hline 1980 & 1.625 .422 & 1992 & 1.692 .078 & 2004 & 4.793 .703 & & \\
\hline 1981 & 1.357 .879 & 1993 & 1.641 .138 & 2005 & 5.358 .170 & & \\
\hline
\end{tabular}

Percebe-se, pois, um grande fluxo de viajantes de fora e de dentro do País, fazendo com que para o turismo, como atividade econômica, estabeleçamse novas necessidades quanto à hospitalidade comercial empreendida.

Nesse sentido, a formalização de procedimentos e necessidades para a questão, quanto à qualidade dos serviços prestados, em relação à segurança e saúde dos viajantes, torna-se urgente, já que, politicamente, é inexistente no País. Silva adverte:

No campo prático, as iniciativas disponíveis de atenção ao turista brasileiro limitam-se à oferta de aconselhamento médico individual antes da viagem, recomendação de vacinas necessárias previstas ou não no Programa Nacional de Imunização (PNI) e assistência após a viagem. Esses serviços são considerados projetos de pesquisa e extensão em instituições acadêmicas de iniciativa da medicina de viagem. Apesar da inserção dos Centros de Referência para Imunobiológicos Especiais (CRIE) nessas unidades, essas ações não foram absorvidas como política de governo que pudesse garantir atendimento a toda população de viajantes (2011, p.16-17). 
Apesar da constante melhoria empreendida pelo Ministério do Turismo brasileiro por meio dos programas de capacitação, que envolvem desde projetos voltados para a manipulação de alimentos e sua comercialização até campanhas de sexo seguro e diminuição do turismo sexual, ainda não há uma política voltada para a segurança e saúde do viajante no Brasil quiçá para a capacitação da mão de obra direta envolvida no processo.

Não obstante, o Brasil é signatário de vários tratados e convenções internacionais relacionados com normas de segurança e saúde, porém são ações setorizadas por modal turístico.

$\mathrm{Na}$ área de cruzeiros marítimos, a pesquisa científica, incluindo artigos sobre o assunto, limita-se a explorar os aspectos comerciais da atividade, sem a preocupação com as questões de segurança, e, mesmo quando se trata da questão de saúde a bordo, os estudos limitam-se ao levantamento de doenças relacionadas com os tripulantes, conforme pesquisa realizada nas bases de dados Scielo, Scopus, Pubmed e International Maritime Health.

Aos cruzeiros marítimos no Brasil dá-se uma atenção especial em razão de seu crescimento elevado na última década, principalmente em virtude da legalização desse segmento recentemente, pois, no País, os navios estrangeiros encontravam, desde a primeira Constituição do Brasil República (a de 1891, art. 13, parágrafo único), uma dificuldade que só foi resolvida em 1995, com a Emenda Constitucional n. ${ }^{\circ}$, em que a navegação de cabotagem, que é realizada ao longo da costa, foi permitida aos navios de bandeira estrangeira. Muitos navios que vinham para o Brasil só podiam fazer uma parada técnica que, geralmente, acontecia nos portos de Salvador, Rio de Janeiro ou de Santos, e, em seguida, rumavam para o exterior (FUJITA 2005).

Conforme FUJITA (2005), o reinício da navegação de cabotagem com fins de turismo ocorre em 1990 com o navio Funchal. Depois, a atividade turística foi organizada, em 1998, quando da realização da primeira pesquisa de levantamento oficial de dados pela vinda de duas embarcações de grande porte 
para a temporada de cruzeiros marítimos no Brasil (Costa Allegra e Costa Marina). Evidenciou-se, então, a necessidade de infraestrutura e suporte para a atividade (Gráfico1). Até o ano de 1998, portanto, o fluxo de passageiros não era significativo perante os parâmetros da EMBRATUR, órgão responsável à época pelo controle da atividade turística no Brasil. Nas temporadas, havia, no máximo, três embarcações de cruzeiros marítimos realizando pequenos deslocamentos com o transporte de seis mil a nove mil passageiros por temporada, o que era inexpressivo ante o movimento mundial de cruzeiros marítimos (Gráfico 2).

Gráfico 1. Número de navios na costa brasileira

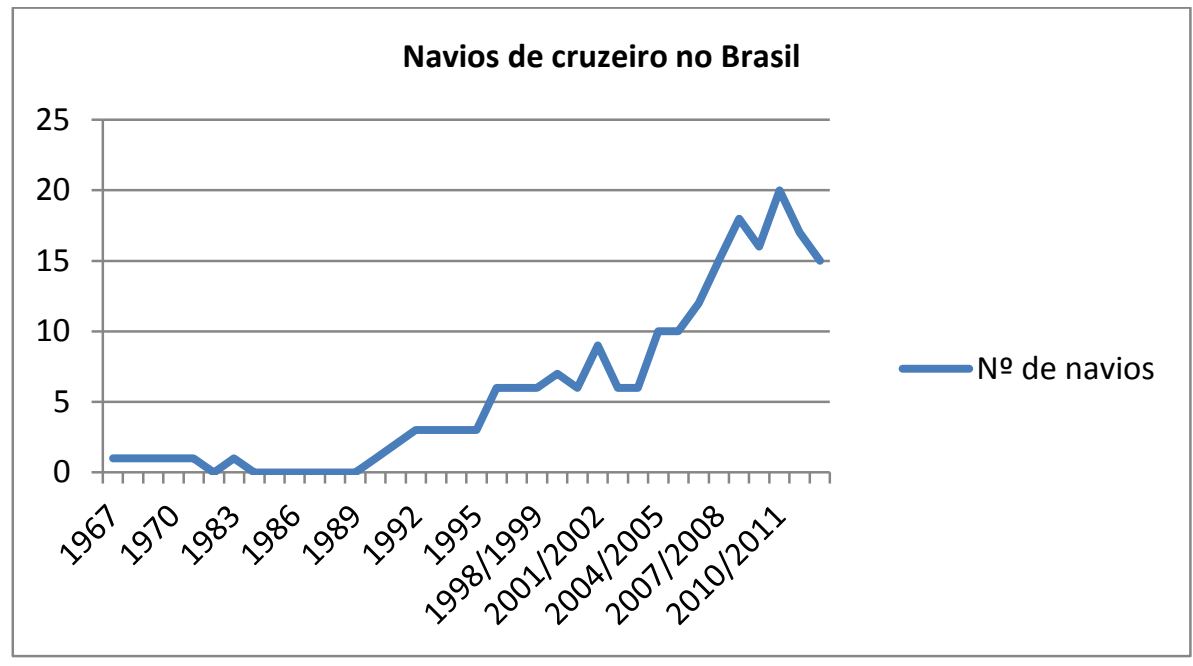

Fonte: Fujita (2005) e Concais (2013). 
Gráfico 2. Número de passageiros em cruzeiros marítimos na costa brasileira

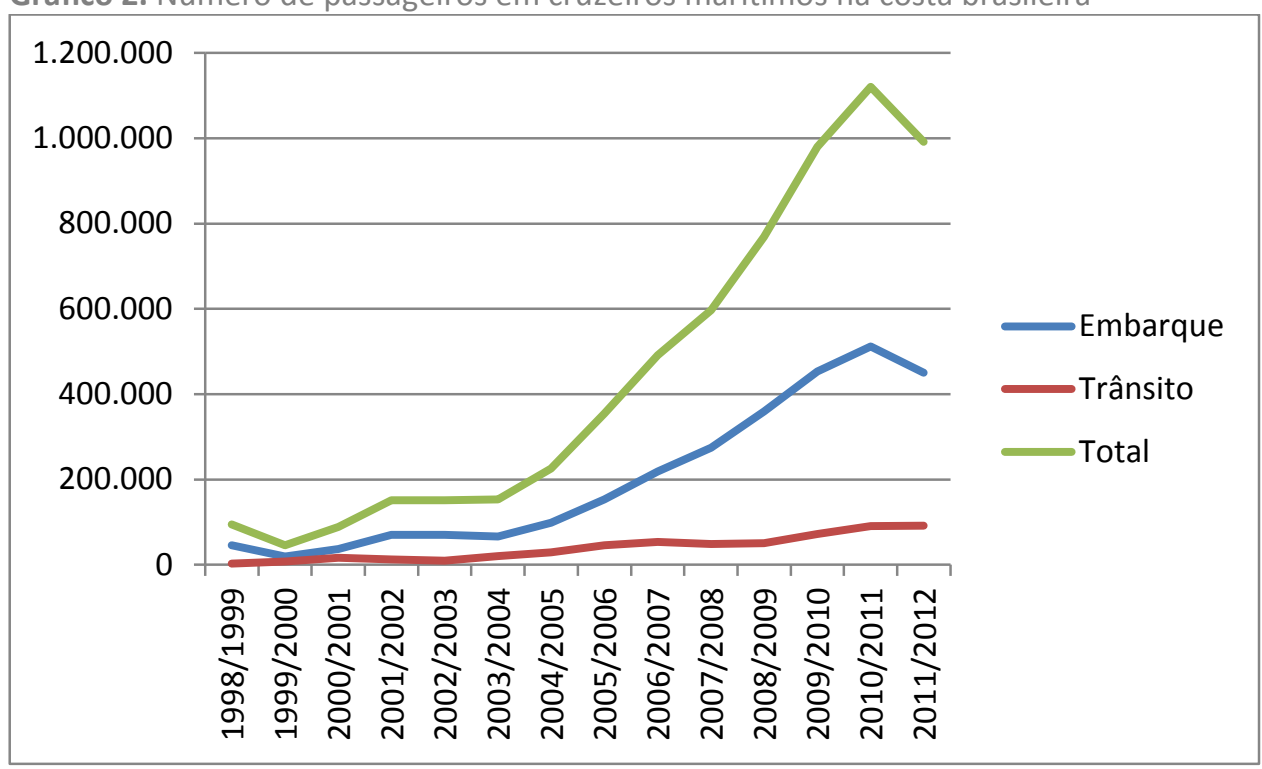

Fonte: Fujita (2005) e Concais (2013).

Analisando-se o gráfico anterior, a diminuição no número de passageiros, a partir de 2011, ocorre em consequência da menor duração da temporada de cruzeiros - de seis para quatro meses - e do número de embarcações disponíveis no litoral brasileiro - de 17 para 15 embarcações. Outros fatores importantes relacionam-se com o aumento do dólar que se reflete diretamente no valor do serviço, diminuindo a possibilidade de consumo, e com os recentes problemas sanitários e de óbitos ocorridos no início da temporada que afastam o interesse do viajante para consumo desse serviço. Não obstante, a quantidade de passageiros ainda continua alta, e, na temporada 2012/2013, totalizaram-se 732.163 passageiros, com um alto contingente de pessoas deslocando-se nos navios em território nacional.

Nos últimos anos, o Brasil tem-se transformado num destino real no fluxo internacional de cruzeiros marítimos, e, segundo dados da ABREMAR (2013), ocupa atualmente o 7.ㅇ lugar como destino de turismo marítimo em fluxo de turistas no mundo, ficando atrás apenas de países com mais tradição no segmento, como Estados Unidos (10,44 milhões de passageiros), Inglaterra (1,7 milhão de passageiros) Alemanha (1,38 milhão de passageiros), Itália (923 mil 
passageiros), Canadá (763 mil passageiros) e Espanha (703 mil passageiros). O montante de passageiros esperado em 2013 foi de 17, 6 milhões de turistas no mundo (CLIA, 2013), e, no Brasil, esperava-se hospedar 694 mil passageiros (4\% do mercado mundial), o que precisou de maior atenção quanto à operação em razão de importância nacional e internacional no contexto estabelecido.

Por esse motivo, no presente artigo, há a construção do conceito de hospitalidade comercial e seu desdobramento nos cruzeiros marítimos, com detalhamento descritivo para os fatores de segurança e saúde a bordo, apresentando-se esse modelo referencial para os demais equipamentos de serviço da área de hospitalidade.

\section{Hospitalidade Comercial: Preceitos de Segurança}

A compreensão do conceito de hospitalidade torna-se possível por meio de duas vertentes: como um fenômeno social, que evoca os mais variados sentimentos e expressões humanas, e ritos e símbolos de cordialidade para com o próximo; e como uma atividade, que dispõe de um potencial de mercado real que supre uma carência atual do público consumidor em relação ao setor de prestação de serviços turísticos.

Figura 1. Esfera da hospitalidade

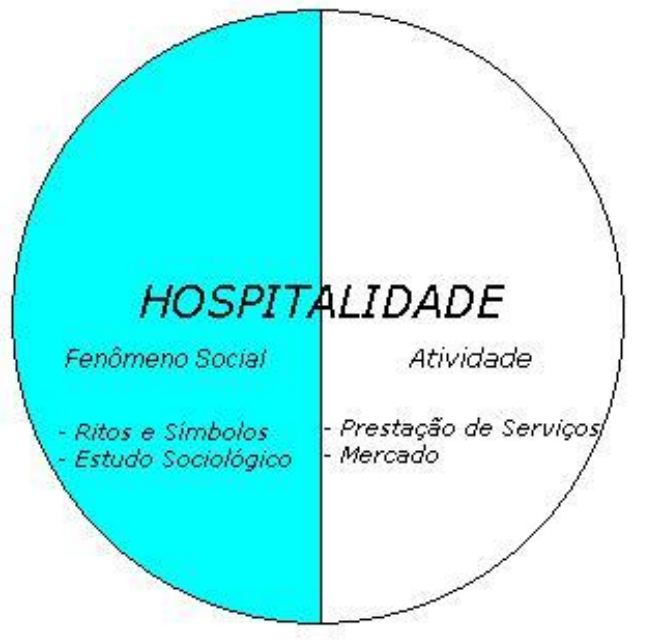

Fonte: Bacal; Fujita, 2005. 
Com essa premissa, é possível construir a evolução desse fato relacionando-o com a história do ato de bem receber no Ocidente, que tem início na Grécia Antiga com a seguinte citação de Guerrier, extraída da Odisseia de Homero:

[...] em muitas culturas, o oferecimento de hospitalidade é visto como responsabilidade dos lares nobres. A oferta de hospitalidade é uma troca que tem por objetivo aumentar o bem-estar tanto do anfitrião quanto do hóspede

[...] o anfitrião beneficia-se do aumento de prestígio e respeito dentro da comunidade (apud GRINOVER. In: DIAS, 2002, p. 26).

Analisando-se essa passagem, constata-se que a hospitalidade é um fenômeno que remete a três ações básicas: dar, receber e retribuir, que, por sua vez, remetem à questão da dádiva, pois a hospitalidade começa como uma oferta que exige sacrifício daquele que a disponibiliza, e é aceita, a posteriori, por alguém que assume uma posição de relativa inferioridade, e que, provavelmente, retribuirá tal regalo, gerando assim uma nova dádiva.

Entretanto quem se doa, a princípio, nesse processo não deve exigir a retribuição da ação, pois ela deve ocorrer de forma espontânea, uma vez que a hospitalidade, como fenômeno, tem origem na relação de cordialidade para com outrem, que se inicia nas doutrinas da religião católica, conhecida atualmente como hospitalidade eclesiástica ou eucarística, que decorre como uma forma de caridade, uma vez que, nos mosteiros, realizava-se o ato hospitaleiro sem fins lucrativos, apenas pregando uma ordem geral samaritana de cuidar bem de qualquer tipo de pessoa, não importando a origem.

Dias assevera:

As palavras hospício (do latim hospitium-i, lugar em que viajantes podiam obter alimento e repouso temporariamente) e hospital (também do latim hospitale-icum, hospedaria ou casa de hóspedes) eram correntes na Europa a partir do século XI e serviam para designar locais, à margem das antigas estradas romanas, destinados a abrigar peregrinos (muitos eram estabelecidos anexos a mosteiros), oferecendo assistência variada, inclusive tratamentos médicos. Nessa época eram utilizados para abrigar pessoas em viagem, doentes, loucos, sãos ou pobres, indiscriminadamente (DIAS, 2002, p.99) 
Essa visão cordial da hospitalidade induz a leitura de que esse fenômeno faz parte da essência humana, uma vez que se busca um instinto anterior, não sendo somente uma norma social como no pensamento grego, mas sim um sentimento materno que se conecta com o ato de proteger e acolher a prole (ser humano), que se transfere para a questão do semelhante.

Ao perceber-se, então, que a hospitalidade é uma motivação humana, compreende-se que o mesmo fenômeno terá características diferentes, tanto para indivíduos, quanto para grupos sociais distintos, pois se trata não apenas de uma ação ou reação ao indivíduo, mas sim de um jogo de interpretação e sensibilidade por parte de quem se propõe a tal ato. Por exemplo, na cultura oriental, a hospitalidade dá-se pela liberdade do indivíduo, isto é, quando uma pessoa é recepcionada, os familiares permitem que ela se isole para que possa descansar de sua jornada, recuperando-se e protegendo o corpo do esforço exigido. Na cultura brasileira, esse ato é inadmissível, uma vez que todos protegem e mostram a receptividade ao indivíduo por meio de muito "calor humano". E mais: todos precisam conversar e demonstrar carinho e afeto à pessoa, mesmo que ela tenha viajado por horas.

Aprofundando-se essa linha de raciocínio, se, na análise, utilizar-se a pirâmide motivacional de Maslow como parâmetro, percebe-se que os dois principais patamares de tal instrumento, relacionados com a sobrevivência humana, são contemplados (necessidades físico-fisiológicas e de proteção); porém o fenômeno da hospitalidade está atrelado às necessidades psicológicas também, tanto na superação do ato de bem receber, quanto na do ato de doarse para essa ação. 
Figura 2. Pirâmide motivacional de Maslow adaptada para a hospitalidade



Fonte: Pirâmide de Maslow adaptada pelo autor (FUJITA, 2005).

No turismo receptivo executado pelos cruzeiros marítimos em relação à pirâmide de Maslow, há uma adaptação para a hospitalidade da seguinte forma: as motivações fisiológicas são obtidas por meio das cabines (acomodação e higiene pessoal) e dos equipamentos de alimentos e bebidas (seis refeições no mínimo já inclusas no preço da viagem); a proteção é contemplada pelo treinamento da tripulação para situações de emergência (Life Boat Drill) e primeiros socorros, e para o cumprimento de normas internacionais de segurança (SOLAS/STCW 78/95); as motivações sociais são providas pelos espaços e equipamentos de lazer a bordo, que, embora "confinem" os hóspedes, permitem que se aproximem mais em razão de diversas atividades de lazer/sociabilização promovidas pela equipe de entretenimento; a estima é 
desenvolvida pelos ritos de etiqueta que evoluem para uma relação de cordialidade, como a "noite do capitão"; e, finalmente, a autorrealização proporcionada pelos eventos de bordo e pelo equipamento turístico, tanto pelo luxo e requinte da infraestrutura, quanto pela atenção e cordialidade da equipe de bordo que trata cada hóspede como um convidado único e especial durante a viagem.

Entretanto se nota que, no universo turístico nacional, na maioria das vezes, não ocorre sequer hospitalidade básica. Não obstante, o fenômeno em sua plenitude exige que se contemplem também as expectativas de ambos os atores, tanto receptores (receber bem), quanto recepcionados (ser bem recebido), culminando na hospitalidade plena, que se torna muitas vezes impossível de atingir-se, visto que, além das expectativas individuais, ainda há variáveis, como cultura e faixa social, que interferem no processo de dar, receber e retribuir.

Ante essa situação, pode-se constatar que a hospitalidade incondicional de Derrida ${ }^{1}$, tende a ser, possivelmente, uma utopia à medida que a receptividade entre as pessoas diminui nos grandes centros por causa dos fatores citados anteriormente.

Assim, assevera Alves:

Nossa observação pessoal, no entanto, como brasileiros, nos permite perceber que, infelizmente, não é assim - como bem público - que a maior parte dos moradores de nossas regiões metropolitanas vive e experimenta a cidade. Por isso, ao contrário do que deveria ser, a cidade grande é vista pela grande massa como causa de sacrifícios, prejuízos e frustrações (ALVES, 2001, p. 42).

\footnotetext{
${ }^{1}[\ldots]$ a hospitalidade absoluta exige que eu abra minha casa e não apenas ofereça ao estrangeiro (provido de um nome de família, de um estatuto social de estrangeiro etc.), mas a outro absoluto, desconhecido, anônimo, que eu the ceda lugar, que o deixe vir, que o deixe chegar, e ter um lugar no lugar que ofereço a ele, sem exigir dele nem reciprocidade (a entrada num pacto), nem mesmo seu nome (DERRIDA, 2003, p. 23-25).
} 
Os problemas citados relacionam-se com o estabelecimento de condições mínimas para a existência da hospitalidade, tanto por parte das pessoas (sociedade), quanto dos polos receptores.

A dinâmica dos grandes centros isola, dessa forma, os moradores por diversos motivos, seja pela conurbação que extingue tanto as áreas livres para convivência/sociabilização, quanto pelas desigualdades sociais ${ }^{2}$, distanciando-os tanto física, quanto geograficamente (desenvolvimento de novas zonas periféricas aos grandes centros urbanos).

Nesse sentido, há esse parâmetro mínimo coexistindo, no decurso dos tempos, com o ser humano, e é uma forma de equilíbrio muitas vezes forçada, que, mesmo assim, tem permitido a continuidade do que se chama sociedade. Eis como Mauss explana:

Em todas as sociedades que nos precederam e que ainda nos rodeiam, e mesmo em numerosos costumes de nossa moralidade popular, não existe meio-termo: confia-se ou desconfia-se inteiramente; depor as armas e renunciar à sua magia, ou dar tudo; desde a hospitalidade fugaz até às filhas e bens. Foi em estados deste gênero que os homens renunciaram a seu ensinamento e aprenderam a empenhar-se em dar e retribuir. É que eles não tinham escolha. Dois grupos de homens que se encontram podem fazer apenas duas coisas: ou afastar-se - e, caso suspeitem um do outro ou se desafiem, lutar - ou tratar-se bem. Até direitos bem próximos de nós, até economias não muito distanciadas da nossa, são sempre estrangeiros com os quais se "trata", mesmo quando são aliados. [...] É opondo a razão ao sentimento, opondo a vontade de paz às bruscas loucuras desse gênero, que os povos conseguem substituir pela aliança, pela dádiva e pelo comércio a guerra, o isolamento e a estagnação (MAUSS, 1974, p.182-183).

Percebe-se, pois, que a sociedade se priva de elementos no intuito de permitir a sobrevivência da cordialidade, da fraternidade e da igualdade entre os semelhantes, tentando, dessa forma, diminuir o distanciamento físico-geográfico e social entre seus membros. Esse cenário poderia ser mais produtivo para o

$2 \mathrm{O}$ aumento do número de pessoas nos grandes centros faz, muitas vezes, com que os salários diminuam ou se aumente o contingente de desempregados das localidades, bem como a diminuição da infraestrutura básica e de suporte ou até sua inexistência, principalmente nos bairros periféricos. 
fomento da hospitalidade plena, porém restam resquícios de tais valores que facilmente podem transformar-se em produtos para serem vendidos às pessoas.

Morin comenta essa situação:

A indústria cultural deve constantemente suplantar uma contradição fundamental entre suas estruturas burocratizadas e padronizadas e a originalidade do produto que ela fornece. Seu funcionamento se fundamenta nesses dois antitéticos: burocracia/invenção, padrão/individualidade (MORIN, 1962, p. 27).

O fenômeno do singular para o coletivo retira não somente o fator de primazia, mas também propicia a vulgarização e a banalização das culturas, não apenas pelo fato de tornar-se um produto, mas também por deixar bem claro que o exclusivo é destinado a poucos, que é o fenômeno inverso desse processo.

Deve-se ressaltar essa situação, uma vez que a hospitalidade se tem encaminhado para esse patamar, principalmente no viés comercial, tendo a referida conotação, que, no dito popular, se transforma para a situação de que, quanto mais se paga, melhor será a receptividade de quem recebe e melhores serão as condições de recepção do indivíduo.

Atentando para o que foi exposto até o presente momento e na busca de uma possível definição que englobe e encerre os conflitos (guerras) da verve humana, é importante ler a seguinte passagem de Lévi-Strauss:

Existe uma transição contínua da guerra às trocas e das trocas aos intercasamentos. E a troca das noivas é apenas o termo de um processo ininterrupto de dons recíprocos, que realiza a passagem da hostilidade à aliança, da angústia à confiança, do medo à amizade (LÉVI- STRAUSS, 1982 [1949], p.107).

A hospitalidade, compreendida pela linha francesa de pensamento apresentada, representa, então, um fenômeno social que se desenvolve por meio da relação harmônica e desinteressada entre dois atores - o hospitaleiro e o hóspede - em que o primeiro é responsável por receber, acolher, alimentar, 
entreter e proteger um ser que necessita de caridade, sem esperar qualquer retribuição dele.

Percebendo-se essa situação, deve-se buscar na hospitalidade a origem mais remota (citada no início deste capítulo), interpretando-a como um sentimento humano que foi absorvido pela sociedade, e, num segundo momento, como um desdobramento de relações que servem não apenas a interesses de classe, mas também a bens maiores: a sobrevivência, a manutenção e o equilíbrio da ação de coexistência em sociedade.

\section{A Hospitalidade Comercial e seu Desdobramento nos Cruzeiros}

\section{Marítimos}

Conforme apresentado no item anterior, a hospitalidade é um fenômeno psicossocial que demanda atenção em sua prática, principalmente no setor comercial, em que há possibilidade de desvirtuação total da dádiva para uma ação puramente mercantil.

Grinover assim define essa postura:

Hoje, o conceito de hospitalidade estende-se para além dos limites de hotéis, restaurantes, lojas ou estabelecimentos de entretenimento. Isso implica a necessidade de recorrer a análises de caráter histórico, epistemológico e empírico das ações que são empreendidas na área da hospitalidade (apud DIAS, 2002, p. 27).

A hospitalidade comercial, então, deve seguir a seguinte diretriz para que realmente promova o fenômeno da hospitalidade:

A submissão ao mercado afasta o setor de questões básicas da hospitalidade. A ideia de acolhimento, de receber o outro, que está na origem da hospitalidade, assume dimensões que apontam para uma nova ética, uma política voltada para o acolhimento, o bem-estar. O planejamento que não considera as grandes minorias marginalizadas constituídas pelos meninos de rua, migrantes, desempregados, não leva ao desenvolvimento econômico, mas ao agravamento das desigualdades (DENCKER, 2004, p.19). 
Evitando-se tal condição puramente comercial, pode-se imaginar e até se ter a construção de um modelo de prestação de serviços que realmente agregue os valores humanos e de segurança citados no item anterior.

A concretização da hospitalidade comercial em moldes humanos não é uma mera busca conceitual, mas uma necessidade preeminente, que dita fluxos e até a escolha propriamente dita do consumidor.

Affolter adverte:

O consumidor do futuro não só aprofundará seus conhecimentos pessoais e suas competências, como também se tornará mais e mais exigente. A transparência do mercado aumentará e os consumidores esperarão receber detalhes e informações relevantes sem ter de se preocupar em coletar esses dados. Aqueles em que as seleções e as tomadas de decisões eram feitas apenas com base nos preços - exceto pelas ofertas que são realmente verdadeiras barganhas - não existem mais (AFFOLTER apud LOCKWOOD; MEDLIK, 2003, p. 254).

A hospitalidade comercial, então, deve ser um desdobramento do fenômeno social do "bem receber" para uma atividade economicamente viável. Compreende-se esse conceito, no presente trabalho, como uma atividade comercial que oferta a prestação de serviços turísticos de qualidade, que devem atender aos padrões econômico-financeiros (custo e infraestrutura) estabelecidos pela empresa fomentadora do processo, mas, principalmente, contribuir para o bem-estar e a segurança do consumidor, atendendo a suas necessidades básicas de acolhimento (retomando-se a pirâmide de Maslow), concretizando e até superando os desejos e as expectativas do hóspede/convidado durante o processo.

Tendo-se esse referencial, a retomada de alguns ritos e símbolos de hospitalidade torna-se imprescindível no processo, além da elevação dos parâmetros de qualidade e segurança dos serviços já prestados atualmente, sem se esquecer de que tais atividades devem gerar uma ação de responsabilidade 
social e manter, na medida do possível, o estabelecimento de relações, não somente mercantis, mas também de caráter social.

Analisando-se esse cenário, pode-se perceber que os cruzeiros marítimos apresentam tais características, principalmente por manter vivas algumas tradições do bem servir, adaptando-as aos diferentes nichos de mercado.

Veterans of this business observe that while early cruises were different from those of today, many things remains the same. "We do today essentially what we did then", says Rod McLeod, Royal Caribbean's Executive Vice President of Marketing, Sales, and Passenger Services. "The only things that have changed are the type people we do it for and the way that we do it". He adds, "We have to do it differently because the people have changed. One example is how we handle smokers. There was no issue the, for instance, about smoking in the dinning room" (DICKINSON; VLADIMIR, 1997, p. 38) ${ }^{3}$

Nota-se então que há certa nostalgia, nos serviços prestados a bordo de um navio, expressa em determinados momentos, por exemplo, o do jantar que ainda mantém uma estrutura de serviço completo, além do cerimonial que o precede, principalmente na "noite do capitão", em que ele recebe os convidados para um jantar de gala, que representa a cerimônia de hospitalidade máxima a bordo, e oferece, oficialmente, sua residência aos convivas.

Outro serviço tradicional de hospitalidade é a recepção dos passageiros com o tradicional welcome drink, coquetel de boas-vindas em que se saúda o hóspede no início da viagem, mostrando-lhe que pode desfrutar dos serviços de bordo, mesmo sem ter efetuado ainda o processo de check-in.

Dando andamento ao processo de hospitalidade comercial, surge a questão de equidade na prestação de serviços nas áreas públicas, isto é,

\footnotetext{
3 Tradução livre do autor: Os veteranos deste segmento de negócios observam que, apesar dos primeiros cruzeiros serem diferentes dos atuais, muitas coisas ainda se mantêm da mesma forma. "Nós fazemos hoje essencialmente o mesmo que sempre fizemos", diz, Rod McLeod, vice-presidente executivo de Marketing, Vendas e Serviços aos Passageiros da Royal Caribbean. "As únicas coisas que têm mudado são os tipos de público que atendemos e a forma como o fazemos." Ele complementa ainda que "nós temos de fazer de maneira diferente porque as pessoas mudaram. Um exemplo é como trabalhamos com os fumantes. Não há possibilidade, em hipótese alguma, de que eles fumem no salão de jantar".
} 
conforme o conceito de Derrida (hospitalidade incondicional), nos cruzeiros marítimos, o passageiro é possivelmente tratado com distinção e cordialidade, não importando vestimenta, credo, ou etnia. O passageiro é compreendido como uma pessoa única, por isso é necessário atender a todos os seus desejos, muitas vezes, sem que ele os solicite diretamente ${ }^{4}$. Alguns podem relacionar esse fato com a questão da gorjeta, isto é, os funcionários estariam propensos a dar um tratamento especial somente pelo fato de que receberão financeiramente ao final do processo; não obstante, a ação é opcional e variante quanto ao valor, dependendo diretamente do cliente sua existência.

O encerramento da viagem é outro momento inesquecível no processo de hospitalidade, culminando com o jantar de despedida, finalizado com a entrada dos garçons no salão de jantar, completamente escuro, iluminados pelos bolos flamejantes (Alaska Cake) e que se encerra com uma salva de palmas seguida dos agradecimentos dos funcionários que afirmam o prazer de ter servido aos clientes durante a viagem. Realizam-se, após, votos de ambas as partes, além da troca de cardápios autografados pela equipe de serviço das mesas (maître, sommelier, barman, garçons e cumins) e pelos clientes.

A segurança e o bem-estar dos passageiros são garantidos pelas normas internacionais advindas da IMO - International Maritime Organization - (o Brasil é signatário das convenções oriundas dessa instituição), órgão vinculado à Organização das Nações Unidas, estabelecidas pela SOLAS - Safety of Life at Sea - que, além de estabelecer normas e parâmetros para a infraestrutura de uma embarcação, trata também de fluxos e operações para segurança e bem-estar da tripulação e dos passageiros nos diferentes cenários de risco.

Tais ações e outros diferenciais em relação aos demais meios de hospitalidade geram vantagens para os cruzeiros marítimos, apresentando

\footnotetext{
${ }^{4}$ No treinamento dos recursos humanos, trabalha-se a questão da leitura corporal, que é imprescindível no processo de atendimento ao cliente, uma vez que determinados gestos indicam necessidades ou desejos, que devem ser percebidos pelo staff de bordo.
} 
características peculiares ao setor que são fatores de motivação e de satisfação do passageiro. Eis tais características:

- A intensa programação de atividades - atualmente, nos cruzeiros, oferece-se uma extensa programação de lazer, que atinge os mais diversos públicos, e faz com que os turistas não precisem preocupar-se com opções de divertimento como acontece nos pacotes turísticos.

- As facilidades de integração - por ser um ambiente restrito onde as pessoas estão despreocupadas, há uma maior facilidade de integração entre os passageiros, que usufruem das mesmas áreas de lazer e participam das mesmas atividades, além de estar em um ambiente descontraído, o que facilita a aproximação entre eles.

- A atenção aos diferentes nichos de mercado - os diferentes mercados podem ser explorados por meio de diversos serviços ou atividades de lazer. $\mathrm{O}$ atendimento prestado também pode variar de acordo com o público (mais formal ou informal, por exemplo). Além disso, existem diferentes tipos de navios, feitos para atender a todos os gostos, além de roteiros diversificados.

- Conhecer diversos lugares numa só viagem e em curto espaço de tempo - os cruzeiros atuais podem durar de três a 22 dias, além daqueles que passam o ano todo navegando ou realizam a chamada "volta ao mundo". As viagens permitem ao turista conhecer, no mínimo, dois lugares diferentes, quando dos minicruzeiros, pois o navio pode navegar à noite e, de dia, ficar aportado em algum lugar. Isso seria impossível para qualquer outro tipo de viagem sem que fosse cansativo para o turista, obrigando-o a fazer, várias vezes, check-in e check-out, além de 
precisar arrumar constantemente a bagagem. Mesmo que os destinos não sejam conhecidos a fundo, a passagem pelas localidades permite que os turistas conheçam um pouco dali, para que, noutra oportunidade, possam visitá-las com mais calma.

- A questão da novidade além da mudança, quebra da rotina e do desligamento do cotidiano - viajar de cruzeiro, principalmente no Brasil, é uma novidade, pois se começou a explorá-lo nos últimos dez anos. A atividade, por si só, é algo novo. Além disso, viajar a bordo de um navio significa "dormir e acordar" em lugares diferentes a cada dia, ver uma nova paisagem e ter um novo lugar a explorar, podendo até essa nova localidade ser um país diferente, com idioma e cultura próprios, diverso daqueles visitados nos dias anteriores.

- Status - viajar de navio pode ser, para alguns, símbolo de status social. Isso acontece pelo histórico das viagens nos clássicos transatlânticos, onde havia todo um glamour a bordo, tanto de ritos, quanto da própria infraestrutura. Algumas pessoas almejam reviver esse passado ou vivenciar essa experiência como seus antepassados.

- Preço - os preços das viagens de navio caíram consideravelmente em relação ao que se cobrava antes. Os preços, aparentemente mais altos em relação a outros pacotes de viagem, além do status obtido por realizar uma viagem de navio, podem fazer com que muitas pessoas pensem que uma viagem de cruzeiro é cara, mas o que elas não analisam é que, no preço de um cruzeiro marítimo, já estão inclusas hospedagem, alimentação e a programação de lazer, além do transporte, em outros meios, como o aéreo. Vale lembrar que há pacotes de 
viagem em que não se incluem entretenimento e/ou alimentação (em muitos pacotes, às vezes, há o regime de meia pensão ou somente o café da manhã).

- Segurança e saúde - ao contrário dos demais segmentos turísticos nacionais, o setor de cruzeiros marítimos é regulamentado internacionalmente quanto à segurança do viajante, com normas e leis rígidas, advindas da SOLAS - Safety of Life at Sea - , instituída em 1974 e atualizada constantemente.

Ressalte-se que, na convenção SOLAS, fixaram-se normas e parâmetros para a infraestrutura de uma embarcação, estabeleceram-se, também, os fluxos e as operações de segurança e bem-estar da tripulação e dos passageiros nos diferentes cenários de risco. Tal normatização é seguida no País, conforme determinação da Marinha do Brasil, por meio das normas da autoridade marítima para navegação e cartas náuticas (NORMAM 28/DHN).

A criação da ONU, em 1948, permitiu a instituição da IMO - International Maritime Organization - (ou IMCO - Inter-Governmental Maritime Consultative Organization -, até 1982), localizada na Inglaterra, que tornou possível a discussão e adesão às principais convenções propostas e assinadas por diversos países.

O primeiro tratado de proteção e segurança universal para navegação foi a Convenção de Linhas de Carga - Load Lines - que instituiu o limite máximo de carga para não comprometimento da estabilidade e navegabilidade da embarcação, observando a borda livre para cada embarcação, considerada a primeira legislação marítima do mundo, datando seu registro em 2.500 a.C., na ilha de Creta. Assim, as embarcações são inspecionadas periodicamente quanto a cargas e manutenção. Realizou-se a proposta, oficialmente, no Parlamento inglês, por sir Samuel Plimsoll, que solicitou a exigência das indicações das linhas 
de carga no casco do navio. Em 1872, instituiu-se a comissão sobre "Cuidados no Mar" que, em 1876, considerou compulsórias as linhas de carga e, somente em 1894, sua exigência como lei.

Convencionou-se o modelo internacional em 1966, passando a vigorar, em 1968. Sofreu alterações em 1971, 1975, 1979, 1983, 1995 e 2003, além de protocolos para alinhamento com as convenções MARPOL 73/78 e SOLAS.

As normas mais específicas quanto a passageiros são as da STCW International Convention on Standards of Training, Certification and Watchkeeping for Seafarers - convenção internacional que estabelece padrões de treinamento, certificação e vigilância marítima para capacitação de tripulantes de embarcações para salvaguarda da tripulação em geral. Essas normas substituíram o modelo anterior que dotava os governos locais de tal responsabilidade, e são invariavelmente distintas de país para país. Os padrões mínimos seguidos podem ser ultrapassados e apresentam artigos relacionados com a inspeção pelo Estado de Porto. A Convenção Internacional SOLAS (Convenção Internacional pela Salvaguarda da Vida Humana no Mar), por sua vez, nasceu em 1914, como reflexo do naufrágio do Titanic. A evolução do segmento marítimo determinou a constituição de novas convenções efetuadas em 1929 e 1948. Em 1960, reformula-se com a autoridade da IMO, e é revista em 1974 (ainda em vigor, porém, com emendas em 1978 e 1988) com a ratificação de 156 estados.

Essa convenção representa uma das mais importantes no segmento marítimo, pois trata da construção e operação segura dos navios de longo curso e da regulamentação de normas e instalação de equipamentos de bordo, de comunicação, de salvatagem, de incêndio etc.

A fiscalização dos cruzeiros marítimos, no Brasil, fica a cargo de três órgãos: Polícia Federal - responsável pelo trâmite de embarque e desembarque de pessoas e cargas -, Marinha do Brasil - responsável pela supervisão das 
normas de navegação, prioritariamente, e de operação das embarcações, com vistas ao cumprimento das determinações da $I M O$-, e a Agência Nacional de Vigilância Sanitária - responsável pelos aspectos de controle sanitário das embarcações.

Descrevem-se abaixo a infraestrutura de segurança e saúde a bordo, e os serviços de apoio em relação aos problemas de saúde oriundos dessas determinações:

- Farmácia: todo navio dispõe de uma farmácia que tem desde itens de higiene pessoal até remédios mais pesados recomendados pelo chefe médico de bordo em caso de acidentes ou emergências. Todo o custo é do passageiro.

- Insolação: deve-se ter muito cuidado com a insolação por causa da exposição constante nas áreas externas da embarcação. Em caso de queimaduras graves, é preciso contatar o médico de bordo.

- Launch (tender) service: os botes salva-vidas encontram-se estrategicamente posicionados nas embarcações, contendo rotas específicas e número de embarcados controlados no intuito de garantir-se comodidade, agilidade e segurança a passageiros e tripulantes. Estabelece-se o número de vagas, no mínimo, 20\% acima do número total de pessoas embarcadas.

- Lifeboat drill: cerca de uma ou duas horas antes da saída do navio realiza-se o treinamento de segurança com os passageiros. No treino, todos devem estar vestidos com coletes salva-vidas. A orientação passada aos passageiros refere-se aos procedimentos em caso de emergência e à localização das saídas de emergência.

- Cinetose: apesar de os navios atuais serem construídos com sistemas de estabilização e outros tipos de inovação tecnológica, 
que permitem o mínimo de oscilação da embarcação, alguns passageiros sentem-se enjoados, podendo até serem hospitalizados conforme o mal-estar. As piores rotas são o triângulo das Bermudas, o litoral sul brasileiro e a costa africana. Nesses trajetos, deve-se recomendar ao passageiro que realize uma consulta prévia ao médico para que possa levar consigo algum tipo de remédio para enjoo.

- Segurança para embarque: os portos são equipados com detectores de metal e raios-X para evitar que ocorram problemas a bordo. O IMS (International Maritime Security) determina que os portos e as embarcações devam ter um padrão mínimo para operacionalidade, o que estabelece que embarcações e portos devam estar em condições que permitam a segurança total do passageiro. Por esse motivo, todas as embarcações são equipadas com serviço de monitoria por satélite, radar, portas antichamas, cofres individuais, e outros equipamentos que possibilitam a total integridade dos passageiros.

- Segurança a bordo: a segurança dos passageiros é garantida pela existência de coletes salva-vidas localizados na parte superior dos armários das cabines, pelo sistema de incêndio com respiros de mercúrio fixados no teto de toda a embarcação, e pela existência de botes salva-vidas em quantidade superior ao número de passageiros. O sistema de incêndio é equipado com sensores de temperatura e fumaça. Constantemente, a tripulação é treinada para tais eventos e também em caso de naufrágio (um treino semanal), e podem operar com segurança o desembarque dos passageiros. Todos os tripulantes precisam ter certificação. 
- Serviços médicos: todos os navios dispõem de um centro médico, com médicos e enfermeiras disponíveis 24 horas; entretanto é preciso ter muito cuidado quando o passageiro necessita de um tratamento especial a bordo. Nesses casos, é necessário avisar com antecedência, mais precisamente, no ato de reserva. O navio Queen Elizabeth 2 tem dois centros médicos equipados com UTI completa e um necrotério refrigerado para atender o viajante de terceira idade.

É importante destacar que o staff de bordo é composto por profissionais habilitados para operar os equipamentos, prevendo-se sempre a segurança e o bem-estar dos passageiros:

- Capitão: cuja função é comandar toda a embarcação, desde a navegação até os passageiros, com totais poderes para fazer cumprir suas determinações. É, pois, a autoridade máxima do navio.

Staff do capitão: grupo de comando secundário do navio, em que todos têm a mesma escala de importância. Assumem a responsabilidade pela embarcação quando o capitão deixa a ponte de comando. Recebem todas as informações, retransmitindo-as conforme a necessidade do capitão:

- Oficiais de ponte: reais navegadores do navio, divididos, hierarquicamente, em chefe dos oficiais, segundo oficial e oficiais juniores, cujas responsabilidades incluem o controle de todos os equipamentos de segurança a bordo.

- Chefe engenheiro: responsável pelo controle da manutenção de toda a embarcação. Tem conhecimento geral de todos os equipamentos existentes na embarcação. 
- Oficial chefe de rádio: responsável por toda a comunicação do navio com o meio externo, Tem o principal acesso aos controles de climatologia reportados ao capitão. Nos casos de incidente, dispõe de normas específicas e protocolos a serem desenvolvidos.

- Oficial médico responsável: responsável pela equipe médica de bordo, que cuida da saúde de toda a embarcação, desde a tripulação até os passageiros. Tem experiência para controlar epidemias, em caso de contaminação.

- Gerente hoteleiro: responsável pela ordenação de todas as funções de acomodação e hospedagem referentes às áreas comuns, às cabines e aos serviços de bordo que são prestados, além de higiene, segurança e controle de manutenção.

- Gerente de alimentos e bebidas: responsável por todos os setores de alimentação do navio, desde o estoque até a preparação e o serviço de turno. Gerencia todos os funcionários dos restaurantes e supervisiona a qualidade dos alimentos, das bebidas e do serviço de bordo, até mesmo do cumprimento das normas de manipulação e boas práticas.

- Controller de segurança higiênico-sanitária e alimentar: responsável pelo controle higiênico-sanitário das estruturas e principalmente dos processos a bordo, com ênfase no setor de alimentação.

Ressalte-se que todos os tripulantes são obrigados a realizar o curso de STCW 78/95 - uma certificação da IMO (International Maritime Organization) -, que instrui o treinamento básico de segurança para navios e inclui segurança pessoal e responsabilidade social, controle de crises e aglomerações, comportamento humano, primeiros socorros elementares, prevenção e combate de incêndio, técnicas de sobrevivência pessoal e procedimentos de 
emergência. Assim, todos os funcionários estão aptos a prestar socorro aos passageiros.

A estrutura complexa que envolve tanto o aspecto de recursos humanos, quanto o de equipamentos e serviços de segurança é o resultado de uma regulamentação extremamente severa que precisa ser seguida em embarcações comerciais de passageiros que aportam no País.

Em problemas relacionados com surtos e epidemias, há contramedidas que vão desde a obrigatoriedade de comunicação por parte da embarcação até ações de quarentena e investigação para controlar a contaminação das populações internas (turistas e tripulação) e externas (localidades receptoras) dos navios - medidas adotadas pelos órgãos de fiscalização e controle das embarcações.

Quanto aos demais equipamentos da área de hospitalidade no Brasil, os disponíveis em cruzeiros marítimos merecem destaque, se comparados, por exemplo, com os meios de hospedagem e de eventos. Percebese, assim, que, apesar de haver uma normatização nacional para os aspectos de segurança em edificações (como NBR 13.994/00, NBR 9.077/01), oriunda da Associação Brasileira de Normas Técnicas, o fato é que cada unidade da federação dispõe de autonomia legislativa sobre o assunto. Dessa forma, a obrigatoriedade de equipamentos simples como sprinklers pode variar de localidade para localidade. Parâmetros referentes à acessibilidade (NBR 9.050), que seriam notoriamente obrigatórios, acabam por ser meramente seguidos, ou muitas vezes grosseiramente adaptados às construções, mesmo nas mais recentes. Não há uma normatização específica para salvaguarda dos consumidores recebidos por esses estabelecimentos. Por exemplo, os equipamentos de segurança - como instruções detalhadas de rota de fuga em caso de incêndio. Em muitos hotéis e espaços de eventos, inexistem "mapas de fuga" e pessoal capacitado para atendimento em situações extremas - como 
equipe treinada para realizar o combate a incêndios e para primeiros socorros , embora seja um projeto de lei federal, mas sem caráter obrigatório para todos os estabelecimentos (somente naqueles que recebem acima de três mil pessoas).

Constata-se, assim, que o complexo de serviços denominado cruzeiro marítimo apresenta, estruturalmente, condições maiores de garantir a segurança e o bem-estar do turista brasileiro do que qualquer outro tipo de equipamento no setor de turismo receptivo, principalmente por falta de uma regulamentação nacional que normatize e fiscalize o bem maior que é a vida do turista.

\section{Considerações Finais}

O conceito de hospitalidade comercial precisa ser desenvolvido no Brasil com vistas à segurança e ao bem-estar dos viajantes, tanto em equipamentos, quanto em polos para que as condições básicas e de atratividade se tornem sustentáveis e financeiramente viáveis.

O Brasil tende a ser um destino real nos próximos anos, principalmente para o fluxo internacional, basta relembrar os dados apresentados em relação ao número de turistas estrangeiros nas últimas temporadas e nos grandes eventos (Copa do Mundo de Futebol e Olimpíadas). Por esse fato, constata-se a possível geração de divisas, não sendo um fluxo unilateral como ocorre no contexto atual, no qual os valores obtidos com as vendas das viagens simplesmente deixam o País, restando parcos valores.

Os cruzeiros podem ser a fonte primária de entrada de capitais para diversas localidades, principalmente quando do desembarque dos turistas, uma vez que se utilizam dos serviços locais, movimentando a economia das cidades portuárias e gerando novos empregos e fontes de renda. 
Nesse sentido, torna-se necessário o desenvolvimento de uma política real para a segurança e o bem-estar dos viajantes no País, uma vez que normas e regras se limitam às práticas voltadas à infraestrutura, porém, não em relação à capacitação técnica da mão de obra.

As normas internacionais usualmente suprem as necessidades do setor turístico e são empreendidas por políticas internas de companhias estrangeiras, como as normas e políticas que doutrinam o trabalho dos funcionários do segmento hoteleiro, ordens emanadas de manuais de práticas e operações de redes e cadeias internacionais.

A segurança e o bem-estar dos passageiros em trânsito no Brasil ainda são matérias pouco exploradas em termos de políticas públicas e, muitas vezes, são regidas e supervisionadas por convenções e normas internacionais, e o Brasil, por ser signatário, cumpre-as por demanda.

O segmento de cruzeiros marítimos dispõe de uma das convenções de segurança e bem-estar mais completa no contexto atual, o que possibilita sua reinterpretação para o desenvolvimento de uma ação mais efetiva do governo brasileiro em vista de sua negligência no contexto atual, sobretudo na questão de capacitação da mão de obra envolvida no processo turístico. A solução desse impasse deve ocorrer com a união do Poder Público e dos profissionais do segmento, para que, juntos, alcancem todo o potencial de hospitalidade em solo nacional.

Portanto o fomento de novos estudos e pesquisas sobre o assunto tornase necessário para o desenvolvimento do fenômeno de hospitalidade com suas prerrogativas e premissas que garantam a vinda de turistas com segurança ao País, fato ainda negligenciado pelas autoridades locais, o que corrobora com o não desenvolvimento econômico das localidades portuárias, mas, principalmente, a afirmação do País como um destino turístico e de hospitalidade sólido tanto no âmbito nacional, quanto no internacional. 


\section{Referências}

AFFOLTER, D. O mercado do turismo: novos desafios. In: LOCWOOD, A.; MEDLIK, S. Turismo e hospitalidade no século XXI. São Paulo: Manole, 2003.

ALVES, J. Metrópoles: cidadania e qualidade de vida. São Paulo: Moderna, 1997.

BRASIL. Marinha do Brasil. Ministério da Defesa. Normas da autoridade marítima para navegação e cartas náuticas: NORMAM 28 / DHN. Disponível em: <http://www.imo.org/about/conventions/listofconventions/pages/internationalconvention-for-the-safety-of-life-at-sea-(solas),-1974.aspx>. Acesso em: 27 jun. 2013.

BRASIL. Ministério do Turismo. Dados e Fatos (Org.). Anuário Estatístico 2013: Ano base 2012. Disponível em: <http://www.dadosefatos.turismo. gov.br/dadosefatos/anuario/>. Acesso em: 6 jun. 2013.

CONCAIS. Estatísticas: terminal marítimo de passageiros Giusfredo Santini CONCAIS S.A. Disponível em: <http://www.concais.com/pt-br/estatisticas/movimentacao>. Acesso em: 16 jul. 2013.

DENCKER, A. F. M. Planejamento e gestão em turismo e hospitalidade. São Paulo: Pioneira Thomson Learning, 2004.

DERRIDA, J. Anne Dufourmantelle convida Jacques Derrida a falar da hospitalidade. Trad. Antonio Romane. São Paulo: Escuta, 2003.

DIAS, C. M. M. (org.). Hospitalidade: reflexões e perspectivas. São Paulo: Manole, 2002.

DICKINSON, R.; VLADIMIR, A. N. Selling the sea: an inside look at the cruise industry. New York: John Wiley \& Sons, 1997.

FUJITA, D. M. Hospitalidade nos cruzeiros marítimos no litoral brasileiro: estudo de caso da Companhia Costa Cruzeiros. 2005. 113 f. Dissertação (Mestrado) - Curso de Mestrado em Hospitalidade, Departamento de Turismo e Hospitalidade, Universidade AnhembiMorumbi, São Paulo, 2005. Disponível em:

<http://www.dominiopublico.gov.br/download/texto/cp001486 .pdf>. Acesso em: 27 jun. 2013.

GUERRIER, Y. apud GRINOVER, L. Hospitalidade: um tema a ser reestruturado e pesquisado. In: DIAS, C. M. M. (org.). Hospitalidade: reflexões e perspectivas. São Paulo: Manole, 2002.

INGLATERRA. International Maritime Organization. United Nations - World Health Organization. International convention for the safety of life at sea (SOLAS), 1974. Disponível em: <http://www.imo.org/about/conventions/listof conventions/pages/ international-convention-for-the-safety-of-life-at-sea-(solas),-1974.aspx >. Acesso em: 27 jun. 2013.

. International convention on standards of training, Certification and watchkeeping for seafarers, 1978. Disponível em: http://www.imo.org/OurWork/HumanElement/TrainingCertification/Pages/STCWConvention.asp x. Acesso em: 27 jun. 2013.

LÉVI-STRAUSS, C. Guerra e comércio entre os índios da América do Sul. In: SCHADEN, Egon (org.), Leituras de etnologia brasileira. São Paulo: Companhia Editora Nacional, (1976 [1942]). 
MAUSS, M. Ensaio sobre a Dádiva: forma e razão da troca nas sociedades arcaicas. In: Sociologia e antropologia. São Paulo: EPU/Edusp, (1974 [1923-1924]).

MORIN, E. Cultura de massas no século XX: o espírito do tempo. São Paulo: Forense, 1962.

ORTIZ, R. A moderna tradição brasileira: cultura brasileira e indústria cultural. São Paulo: Brasiliense, 1995.

SILVA, V. H. M. A saúde do viajante na visão de três atores: gestores da saúde pública, gestores do turismo e o turista. 2011. 132 f. Tese (Doutorado) - Curso de Saúde Pública e Meio Ambiente, Escola Nacional de Saúde Pública Sergio Arouca, Fundação Oswaldo Cruz, Rio de Janeiro, 2011. 


\section{Dennis Minoru Fujita}

Professor Convidado do Curso de Especialização em Gastronomia - Universidade de Guarulhos Professor Convidado do Curso Superior de Tecnologia em Gastronomia - Univille Bolsista CAPES

Doutorando do Programa de Pós-Graduação em Medicina Tropical da USP

Mestre em Hospitalidade pela Universidade Anhembi Morumbi (2005)

Bacharel em Turismo pelo Centro Universitário Ibero-Americano (2001)

dmfujita@usp.br

Av. Dr. Enéas de Carvalho Aguiar, 470 - Prédio I

Cep: 05403-000 - Cerqueira César - São Paulo - SP

\section{Heitor Franco de Andrade Júnior}

Professor Associado da Faculdade de Medicina e do Instituto de Medicina Tropical de São Paulo da USP

Chefe do Laboratório de Protozoologia do Instituto de Medicina Tropical de São Paulo da USP Responsável pelas disciplinas de graduação em saúde em viagens para a graduação em Turismo da ECA-USP

Pesquisador em Doenças Tropicais e saúde internacional Livre-docente em Patologia de Moléstias Transmissíveis

Doutorado em Patologia

Especialização em Residência Médica Em Clínica Médica e Reumatologia

Graduado em Medicina

hfandrad@usp.br

Av. Dr. Enéas de Carvalho Aguiar, 470 - Prédio I

Cep: 05403-000 - Cerqueira César - São Paulo - SP

Agradecimento/Financiamento CAPES e LIM - 49/HCFMUSP 